\title{
ARTIGOS
}

\section{CURRÍCULO ESCOLAR E DEFICIÊNCIA: CONTRIBUIÇÕES A PARTIR DA PESQUISA-AÇ̃̃O COLABORATIVO-CRÍTICA}

RITA DE CÁSSIA BARBOSA PAIVA MAGALHÃES • MARCIA TORRES NERI SOARES

\section{RESUMO}

Este artigo tem como objetivo analisar o currículo de uma escola pública, em particular aspectos relacionados à inclusão de estudantes com deficiência expressos no espaço escolar e em situações coletivas de uma formação continuada desenvolvida na referida escola. Com base numa pesquisa-ação colaborativo-crítica no contexto da educação básica junto a 26 professores e um intérprete de Língua Brasileira de Sinais - Libras -, o estudo revelou não somente a prevalência de padrões homogeneizantes, a exemplo do caso típico de todos os estudantes com deficiência postos juntos em uma mesma turma do ensino regular, bem como a necessidade do espaço formativo para os docentes na escola. Notadamente, os estudos curriculares oportunizam a (re)discussão da inclusão escolar sem desarticulá-la do contexto macro da educação.

PESQUISA-AÇÃO • CURRÍCULO • DEFICIÊNCIA • INCLUSÃO ESCOLAR

\section{SCHOOL CURRICULUM AND DISABILITY: CONTRIBUTIONS OF A COLLABORATIVE CRITICAL ACTION-RESEARCH}

\section{ABSTRACT}

This article aims to analyze the curriculum of a specific public school, in particular the aspects related to the inclusion of disabled students within the school's space and in collective situations of continuous training developed at the school. The research, based on a collaborative-critical action-research in the context of basic education with 26 teachers and one interpreter of Brazilian Sign Language - Libras -, reveals the prevalence of homogenizing standards, as shown by the typical example of placing all students with disabilities in the same regular classes, as well as the need for a formative space for school teachers. Mainly, the curriculum studies bring the opportunity to (re)discuss school inclusion without disarticulation of the macro context of education. 
RÉSUMÉ

L'objectif de cet article est d'analyser les programmes des cours d'une école publique, tout particulièrement les aspects qui se réfèrent à l'inclusion des étudiants handicapés dans l'espace scolaire et dans des situations collectives liées à une experience de formation continue de cette école. Une recherche-action collaborative-critique auprès de 26 professeurs et d'un interprète de la Langue Brésilienne des Signes - Libras -, met en évidence non seulement la prédominance de modèles homogénéisants comme, par exemple, le cas typique de mettre les étudiants handicapés dans des classes régulières, mais aussi la nécessité d'avoir, au sein de l'école, un espace de formation pour les enseignants. Les études des programmes favorisent notamment la (re)discussion de l'inclusiomn scolaire sans la détacher du contexte global de l'éducation.

RECHERCHE ACTION • CURRICULUM • HANDICAP • INCLUSION SCOLAIRE

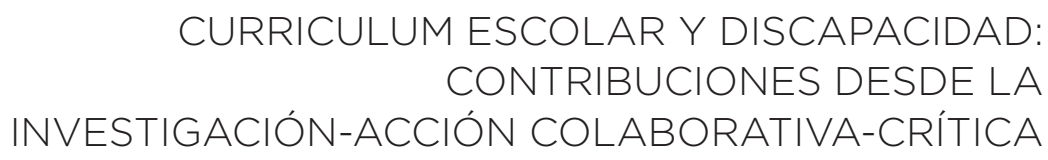

RESUMEN

Este artículo tiene como objetivo analizar el plan de estudios de una escuela pública, en particular los aspectos relacionados con la inclusión de los estudiantes con discapacidad manifestados en el espacio escolar y en situaciones colectivas de una formación continua desarrollada en la citada escuela. Basado en una investigación-acción colaborativa-crítica en el contexto de la educación básica con 26 profesores y un intérprete de Lengua Brasileña de Señales -Libras-, el estudio mostró no exclusivamente la prevalencia de estándares homogeneizantes, como es el caso típico de colocar todos los estudiantes con discapacidad en todos los clase regular, mas también la necesidad de un espacio de formación para los docentes en la escuela. En particular, los estudios curriculares dan oportunidad de (re)discutir la inclusión escolar sin desarticularla del contexto macro de la educación. 

bates acerca da inclusão escolar. Neste artigo, consideramos as pessoas com deficiência representativas do público-alvo da educação especial, haja vista compreendermos a "deficiência" como marca da produção social/cultural comum a estudantes com transtornos globais do desenvolvimento - TGD - e altas habilidades/superdotação, pois, embora cada um dos grupos apresente suas particularidades, a condição incapacitante construída socialmente sobre a deficiência, frequentemente, permeia as condições de vida desse público.

Avanços consideráveis também podem ser identificados no que concerne à matrícula dos estudantes com deficiência no sistema regular de ensino (INEP, 2013), porém persiste o desafio de promover o acompanhamento e a intervenção junto às práticas educativas construídas na educação básica, com o intuito de apoiar professores e demais sujeitos da escola, na tarefa de refletir criticamente e (re)organizar tais práticas.

Supomos que o currículo escolar é um importante elemento na tentativa de potencializar mudanças nas práticas pedagógicas sem particularizar, excessivamente, as especificidades que acompanham o debate acerca da inclusão de estudantes com deficiência na escola regular. Pensar currículo em escola que acolha tais estudantes significa construir propostas curriculares menos rígidas e atentas às demandas de todos os estudantes. 
Como evidenciaram trabalhos seminais como os de Apple (1982, 1989, 1999), o currículo, além de focar os conhecimentos a serem ensinados na escola e as formas de organização do acesso a tal conhecimento, assume o controle social que compreende a organização de regularidades diárias básicas escolares e suas contribuições para o aprendizado pelos estudantes das ideologias hegemônicas, as formas específicas de conhecimento curricular que refletem essas configurações ideológicas e, finalmente, como isso serve para o professor ordenar, guiar e conferir significado à sua própria atividade docente. Assim, a escola, com seu currículo, ensina modus operandi e modus vivendi às gerações mais jovens ao selecionar, classificar, rotular, disciplinar e distribuir desigualmente o saber.

Neste artigo, a inclusão escolar "refere-se a uma proposição política em ação, de incorporação de alunos que tradicionalmente têm sido excluídos da escola, [enquanto a] educação inclusiva refere-se a um objetivo político a ser alcançado" (BUENO, 2008, p. 49) e se personifica em cada escola no projeto pedagógico e nas práticas curriculares desenvolvidas.

Historicamente fomos convidados a pensar sobre as condições que obstaculizam a proposta da inclusão escolar como advindas, somente, da deficiência e de problemas referentes à formação de professores. Pairava a ideia de que o ingresso dos estudantes com deficiência nas classes comuns de ensino, forçosamente, minimizaria o currículo escolar e/ou comprometeria a escolarização destinada aos demais, haja vista a necessidade de atendimento a um grupo em situação de vulnerabilidade escolar, portanto aquém das condições e critérios de ensino e aprendizagem estabelecidos pela instituição escola.

Consideramos, pois, o currículo escolar propício para a discussão acerca da inclusão de estudantes com deficiência, porque possibilita analisar a forma

[...] como a prática se sustenta e se expressa de uma forma peculiar no contexto escolar. O interesse pelo currículo segue paralelo com o interesse por conseguir um conhecimento mais penetrante sobre a realidade escolar. (SACRISTÁN, 2000, p. 30)

A evidente necessidade de estreitarmos relação com o currículo escolar não é nova, afinal os pesquisadores tendem a interrogar "sobre a organização do trabalho na escola: definição dos espaços e dos tempos lectivos, agrupamento dos alunos e das disciplinas, modalidades de ligação à ‘vida activa', gestão dos ciclos de aprendizagem, etc.” (NÓVOA, 2002, p. 25).

A pesquisa empírica que realizamos oportunizou a interlocução com os sujeitos de uma investigação debruçada sobre a análise do currículo escolar com ênfase na inclusão de estudantes com deficiência, notadamente no âmbito da gestão e da sala de aula. Ressaltamos que a 
inclusão de estudantes com deficiência na escola questiona a tradição dos currículos fechados ou a noção - tão comum na perspectiva técnico-instrumental - de que há necessidade de propostas e práticas curriculares extremamente diferenciadas para escolarizar tais alunos.

Nesse sentido, ao nos aproximarmos de uma escola como campo de investigação, problematizamos suas práticas e tomamos a acepção de currículo para além da visão técnico-instrumental, como “uma opção historicamente configurada que se sedimentou dentro de uma determinada trama cultural, política, social e escolar; está carregado, portanto, de valores e pressupostos que é preciso decifrar" (SACRISTÁN, 2000, p. 17).

A intenção de conhecer o currículo escolar permeou nossa estada no campo de investigação empírica: uma escola pública da rede estadual do Rio Grande do Norte, junto a 26 professores dos anos iniciais e finais do ensino fundamental com funções distintas (professores de sala comum, de salas de recursos multifuncionais, diretor, vice-diretor, coordenadores pedagógicos) e um intérprete de Língua Brasileira de Sinais - Libras.

Com base nessas argumentações iniciais, o objetivo do presente artigo é analisar o currículo de uma escola pública, em particular aspectos relacionados à inclusão de estudantes com deficiência em classes comuns de ensino expressos no espaço escolar e em situações coletivas de uma formação continuada desenvolvida com professores e intérprete de Libras da referida escola. O foco principal é a discussão do espaço físico e simbólico dado aos estudantes com deficiência no contexto escolar.

A seguir, apresentamos algumas reflexões de cunho teórico e, na sequência, as bases metodológicas do estudo. Posteriormente discutimos os principais resultados da pesquisa realizada e, finalmente, tecemos as conclusões do texto. Pretendemos, assim, colaborar nos debates sobre o currículo escolar e processos de educação inclusiva.

\section{CURRÍCULO ESCOLAR: POSSIBILIDADES PARA/NA INCLUSÃO DE ESTUDANTES COM DEFICIÊNCIA}

$O$ currículo materializado na escola corresponde não apenas às determinações oficiais, mas também às escolhas e estratégias desenvolvidas pelos professores em dado contexto de ensino e aprendizagem. A concepção de currículo escolar adotada aqui sugere a interpretação de que este "se dá numa situação social de grande complexidade e fluidez [...] seus protagonistas tomam numerosas decisões de prévia reflexão" (SACRISTÁN, 2000, p. 49).

Ao não se limitar às determinações oficiais, o currículo, além dos conhecimentos a serem compartilhados, expressa crenças, valores. Contudo, muitas vezes nos esquecemos de que "o conhecimento que constitui o currículo está inextricavelmente, centralmente, vitalmente, 
envolvido naquilo que somos, naquilo que nos tornamos: na nossa identidade, na nossa subjetividade" (SILVA, 2007, p. 15-16).

Ressaltamos, ainda, que os processos de escolarização são significativamente culturais: "Ocorre que elas [as questões de transmissão cultural da escola] dizem respeito ao próprio conteúdo do processo pedagógico e interpelam os professores no mais profundo de sua identidade" (FORQUIN, 1993, p. 9). Interpelam, assim, formas de pensar o conhecimento e transmiti-lo, bem como formas de pensar quem é o estudante e como ele aprende.

Ao considerar a relação entre educação e cultura como íntima e orgânica, Forquin (1993) salienta a necessidade de discutir a cultura com aprofundamento, ainda que sua posterior relação ocorra de forma fragmentada, ou indireta. Em nosso estudo, nos permitimos considerar as contribuições teóricas do autor e entender a cultura como "conteúdo substancial da educação, sua fonte e sua justificação última: a educação não é nada fora da cultura e sem ela” (FORQUIN, 1993, p. 14). Dessa imbricação decorre a importância em atentar para a cultura escolar, como conteúdo de nossas práticas, dos aspectos enraizados, como que inquestionáveis, em nossas organizações didáticas e de suas interferências na forma como lidamos com os conhecimentos, os diferentes sujeitos aprendentes e mais especificamente com a deficiência no currículo escolar.

Reconhecemos, portanto, as incontestes influências culturais na organização do currículo escolar. Segundo Forquin (1993, p. 24), “uma teoria do currículo supõe sempre levar em consideração o que se passa no interior da 'caixa preta' das salas de aula e das escolas e não apenas o que se passa na entrada e na saída”. O conteúdo subliminar, aspectos implícitos aos processos de escolarização da escola investigada, foi então nossa referência para calcar diálogos sólidos com seus partícipes.

A concepção de deficiência adotada em nosso estudo baseia-se nas condições sociais e culturais, constituintes da identidade humana. Durante muito tempo a abordagem clínico-médica embasou as investigações sobre pessoas com deficiência: "Sua aprendizagem, a partir dessa ótica, só poderia ocorrer em ambientes com estímulos controlados e elegeu-se a repetição e o treino, como forma hegemônica de desenvolver práticas pedagógicas" (MAGALHÃES, 2011, p. 94). Contrariamente à concepção biomédica, demarcadora da patologia, coadunamos com a concepção social. Tomamos por referência as contribuições teóricas de Vygotsky (1988) sobre a constituição social do sujeito. Segundo suas concepções, os sujeitos não se moldam por seus determinantes orgânicos, nem pelos sociais, mas sim nas relações vividas e compartilhadas em seu(s) grupo(s) social(ais). Assim, a deficiência deve ser concebida no contexto das relações sociais mais amplas. 
Defendemos, ainda, a perspectiva de que na escola aprendemos estigmas (GOFFMAN, 1988) e podemos questioná-los; da mesma forma, fomentar atitudes de empatia e reflexão provoca-nos o entendimento de que investigações "com” os sujeitos da educação básica e não "sobre” esses sujeitos podem contribuir na aproximação necessária para refletir sobre as subjetividades implícitas aos processos de escolarização de estudantes com deficiência. Considerar essa participação é um dos mais importantes e difíceis desafios da escola na atualidade. Como postulam Glat e Pletsch (2011, p. 28),

\section{Esse objetivo, porém só será alcançado se o currículo e as práticas pedagógicas das escolas levarem em conta as diversidades e es- pecificidades do processo de ensino-aprendizagem de cada aluno, e não partirem de um padrão de homogeneidade.}

A investigação do currículo nos permitiu adentrar na escola e conhecer suas formas de organização, do ponto de vista tanto do conhecimento escolar quanto das identidades construídas nas interações com as turmas, no manejo da prática educativa, na eleição dos conhecimentos curriculares válidos e no lugar destinado aos estudantes com e sem deficiência nas salas de aula.

O currículo, em nossa investigação, portanto, não foi reduzido a um pacote prescritivo imposto pelas instâncias governamentais, antes reconhecemos as possibilidades, as brechas para o enfrentamento de práticas pedagógicas excludentes. Com tal entendimento, não desconsideramos a conjuntura mais ampla na construção do currículo - as condições estruturais, organizativas, materiais, de bagagem de ideias e significados (SACRISTÁN, 2000) - e ponderamos, notadamente na educação especial, acerca da prevalência da perspectiva técnica do currículo como se a tarefa da inclusão escolar de estudantes com deficiência se resumisse à dimensão técnica do conhecimento e das formas de organização do ensino na escola.

Conforme defendemos, na organização curricular subjazem relações múltiplas entre educação e cultura e, consequentemente, a ausência de modelos prescritivos de organização curricular capaz de atender a todos igualmente, como informa Forquin (1993). Por não haver uma correspondência linear, a cultura escolar apresenta sempre reinterpretações do que deve ser conservado e/ou esquecido no âmbito do currículo escolar, inclusive os conteúdos eleitos como importantes à escolarização e, por isso, incluídos nesse currículo.

Em Apple (1999, p. 42), encontramos um questionamento sobre a eleição do conhecimento de alguns grupos como digno de ser transmitido às gerações mais jovens, “enquanto a história e a cultura de outros grupos mal veem a luz do dia, revela algo extremamente importante 
acerca de quem detém o poder na sociedade”. Num campo de intencionalidades e disputas de poder, dizer sobre o que ensinar e quem são os elegíveis para a aprendizagem escolar, ou quais grupos permanecem com suas manifestações culturais em uma espécie de "limbo", constitui um conteúdo importante às investigações curriculares.

Coaduna com nossa investigação um reconhecido e importante acervo teórico sobre a organização curricular em atenção a estudantes com deficiência (MANJÓN, 1995; AINSCOW, 2001; OLIVEIRA, 2004; MAGALHÃES, 2005; AMARAL, 2006; GONÇALVES, 2006; CARVALHO, 2008; KLEIN; FORMOSO, 2009; LOPES, 2010; SILVA, 2008; 2010; EFFGEN, 2011; FONSECA, 2011; GLAT; PLETSCH, 2011; VIEIRA; 2012; FIORINI; DELIBERATO; MANZINI, 2013), contudo o desenvolvimento de investigações do tipo pesquisa-ação revelou-se importante como caminho na construção de um conhecimento científico acerca de possibilidades na organização do trabalho pedagógico em atenção ao enriquecimento curricular necessário à proposta de inclusão escolar.

A noção de enriquecimento e flexibilização curricular trouxe a possibilidade de dialogar com a escola investigada na perspectiva de construção de reflexões sobre o currículo em ação. Conquanto, em nosso entendimento, a flexibilização é para todos os estudantes com ou sem deficiência, e

\footnotetext{
[...] exige que as mudanças na estrutura do currículo e na prática pedagógica estejam em consonância com os princípios e com as diretrizes do Projeto Político Pedagógico da escola, na perspectiva de um ensino de qualidade para todos os alunos. (FONSECA; CAPELLINI; LOPES JR., 2010, p. 26)
}

Na perspectiva adotada no estudo, tomamos a flexibilização curricular como possibilidade de enriquecimento ao currículo e de acesso aos conhecimentos historicamente produzidos pela humanidade, em contraposição à ideia de redução, ou empobrecimento dos conteúdos e da deficiência como marca definidora e restritiva da capacidade de estudantes com deficiência (GARCIA, 2006).

Portanto, lançar-se ao desafio de pensar um currículo aberto às diferenças (de toda natureza) é fator de enriquecimento para todos no âmbito da cultura escolar, “daí a importância dos professores reconhecerem as limitações de seus alunos, mas desenvolverem uma prática pedagógica que não seja orientada pelas impossibilidades” (MAGALHÃES, 2011, p. 81).

Se historicamente a escola vem operando com base em uma concepção de homogeneização, supomos que a análise de como as regularidades diárias de ensino e de aprendizagem produzem os resultados deve ser seguida por um exame da própria distribuição de conhecimento no 
contexto da cultura escolar. Tal funcionamento interliga concepções e prática dos professores na forma como materializam o currículo.

\section{PESQUISA-AÇÃO COLABORATIVO- -CRÍTICA NO CAMPO CURRICULAR}

Os dados apresentados no presente artigo resultam de pesquisa realizada com uma escola pública, na qual "os membros do público alvo são sujeitos conscientes que colaboram com o pesquisador” (BARBIER, 2004, p. 52). A investigação procedeu de uma solicitação da própria gestão escolar a uma universidade pública federal nordestina de uma intervenção no âmbito da reformulação do Projeto Pedagógico da escola. O contato anterior dessa universidade com o campo de pesquisa permitiu o conhecimento prévio de algumas necessidades dos sujeitos e facilitou tanto a nossa inserção empírica quanto a organização da proposta colaborativo-crítica que desenvolvemos ao longo de um ano de investigação. Tal solicitação coadunou o fato de desejarmos "realizar pesquisas com os profissionais nos contextos escolares e não sobre eles" (PIMENTA, 2006, p. 26).

Do ponto de vista das bases metodológicas, optamos por uma abordagem qualitativa (GONZAGA, 2006; STAKE, 2011) alicerçada na possibilidade de problematizar os fatos em toda sua complexidade e de forma densa. A abordagem nos possibilitou considerar os aspectos subliminares subjacentes às interações de estudantes com e sem deficiência, ao passo que oportunizou condições na produção e análise dos dados.

Consideramos as variadas acepções da pesquisa como processo denominado, por Barbier (1985), de "radicalização política e existencial" da pesquisa-ação, com características e concepções diferentes em cada país. Calcamos o estudo na possibilidade de ouvir, ver e conviver com os sujeitos da escola e com eles pensar/refletir sobre estratégias de ação de propostas curriculares condizentes com o respeito às diferenças e, notadamente, com a existência de pessoas com deficiência no corpo discente e docente da escola.

O estudo realizou-se com base nos princípios da pesquisa-ação colaborativo-crítica (JESUS, 2008; VIEIRA, 2008, 2012; JESUS; ALMEIDA; SOBRINHO, 2005; ALMEIDA, 2004, 2010; GIVIGI, 2007), cuja ênfase recai sobre a elucidação do objeto de estudo concomitantemente à imersão no campo de pesquisa e a decorrente aproximação de seus participantes. A adoção de nossa vertente metodológica, portanto, trouxe implicações para nosso modo de organizar a imersão no campo e o processo de intervenção. Tal processo foi construído na perspectiva colaborativo-crítico, na qual é comum que possíveis lacunas da investigação só sejam preenchidas à medida que se discutam algumas definições, asseguradas e (re)dimensionadas junto aos participantes da pesquisa. 
Elucidamos que o caráter colaborativo-crítico do nosso caminhar metodológico foi um trabalho de conquista não apenas na/para obtenção de determinado resultado, mas também em uma aproximação elaborada com diferentes participantes engajados em dado processo investigativo.

A colaboração foi construída desde o início da pesquisa somando a participação dos 26 professores e um intérprete de Libras. Tais professores ocupavam funções diferenciadas, como na regência de turmas do $2^{\circ}$ ao $9^{\circ}$ ano, coordenação pedagógica, diretoria e sala de recursos multifuncionais - SRM. Com formações iniciais e experiências profissionais variadas, o grupo contribuiu para a constituição de uma formação continuada intitulada Grupo de Colaboração em Inclusão Escolar - GCEI -, em um trabalho marcado por conflitos, consensos e afetos.

Em nosso estudo, assumimos a proposta de formação continuada como possibilidade de problematizar as práticas curriculares desenvolvidas na escola com o foco na inclusão escolar. Quanto ao sentido crítico inerente à vertente metodológica escolhida, reconhecemos a condição estabelecida por Franco (2005, p. 48) de que

[...] a condição para ser pesquisa-ação crítica é o mergulho na práxis do grupo social em estudo, do qual se extraem as perspectivas latentes, o oculto, o não familiar que sustentam as práticas, sendo as mudanças negociadas e geridas no coletivo.

Na investigação realizada assumir o caráter crítico da pesquisa exigiu considerar e questionar práticas e concepções dos participantes, gerando diálogos densos voltados para o currículo escolar.

O processo de construção dos dados ocorreu gradativamente a partir da proposta de formação continuada. O GCEI se constituiu como proposta de intervenção por meio de encontros realizados na própria escola, os quais tiveram a periodicidade quinzenal durante 2013. Cada encontro formativo do GCEI foi denominado de Espaço de Colaborar-ação, no qual objetivamos criar e solidificar momentos para discussão e problematização de situações escolares cotidianas, bem como dos desafios sobrepostos ao professor na tarefa de ajustar as práticas pedagógicas às especificidades dos estudantes, em especial daqueles com deficiência. Era um espaço de socialização das inferências que organizávamos sobre a escola e momento de partilhar e discutir coletivamente.

Tratava-se, assim, de um espaço formativo construído com e na escola, em uma perspectiva de formação docente apontada por Nóvoa (2002, p. 28) não como momento de individualizado de formação, mas como 
uma relação forte entre as escolas e o mundo universitário, por razões teóricas e metodológicas, mas também por razões de prestígio e de credibilidade; Implica formas de divulgação pública dos resultados.

Como instrumentos foram utilizados a observação direta, entrevistas semiestruturadas, análise de documentos e os encontros formativos de Colaborar-ação desenvolvidos no GCEI, que geraram um diário de campo. Estes não obedeceram qualquer rigor cronológico, antes tiveram seus contornos definidos na efervescência de sua realização, considerando tempos e espaços formativos possíveis em uma escola que deve cumprir um intenso ano letivo com aproximadamente 800 horas. Após o encontro de Colaborar-ação inicial, no qual explicamos a proposta da investigação e metodologias dos demais encontros - totalizando 60 horas/aula -, foi gradativamente aflorando e embasando a organização dos próximos encontros. Houve, então, uma forma de retroalimentação contínua entre demandas da escola e objetivos da pesquisa, o que evidencia o caráter colaborativo da investigação.

Ressaltamos, assim, o foco na formação continuada como elemento disparador na construção de uma pesquisa-ação. Reconhecemos, ainda, que qualquer experiência formativa merece ser compreendida no âmbito da discussão mais ampla acerca da formação docente, pois não há como desvincular seu desenvolvimento de aspectos complexos, tais como baixa remuneração, extensas jornadas de trabalho (FERREIRA; FERREIRA, 2004), bem como em uma cultura escolar na qual os espaços formativos docentes ainda não estão incorporados às formas de organização do próprio currículo escolar.

Para registro das situações identificadas durante os encontros do GCEI, utilizamos o diário de campo da pesquisadora e de duas colaboradoras de pesquisa, estudantes da Universidade Federal do Rio Grande do Norte - UFRN. Desse modo, confrontamos de forma coletiva nossas impressões e registros, o que garantiu parte do processo de triangulação desenvolvido durante a análise de dados.

As observações dos espaços escolares e das práticas nas salas de aula de 14 professores participantes do GCEI obedeceram a um roteiro previamente definido e foram realizadas nas salas de aula do $6^{\circ}$ e $9^{\circ}$ anos (não havia matrícula de estudantes com deficiência nos anos iniciais do ensino fundamental) e em outros espaços: pátio, quadra, sala dos professores, sala de recursos multifuncionais, porta da escola, entre outros.

Do grupo de participantes escolhemos critérios para garantir maior representatividade de cada segmento e área do conhecimento e atuação, no que diz respeito à seleção dos participantes a serem entrevistados. Compartilhar os critérios com o grupo pesquisado (contemplar professores dos anos iniciais e finais nas áreas de História/Cultura do RN, 
Educação Física, Ensino Religioso/Arte, Inglês, Matemática, Português, Ciências e Geografia); o tempo de serviço na própria escola e a representatividade de todas as funções exercidas pelos professores da escola: SRM, direção, coordenação pedagógica e do intérprete de Libras foi uma forma de aproximação e respeito aos participantes da pesquisa. Ao todo foram entrevistados 18 professores e um intérprete de Libras.

A análise dos dados dependeu das contribuições dos participantes da investigação, pois nos moldes da pesquisa-ação colaborativo-crítica tal análise é, outrossim, produto de discussões da coletividade. “Isso exige uma linguagem acessível a todos. O traço principal da pesquisa-ação - o feedback - impõe a comunicação dos resultados da investigação aos membros nela envolvidos, objetivando a análise de suas reações" (BARBIER, 2004, p. 55).

Assim, a análise dos dados aconteceu concomitantemente à realização da investigação, pois na pesquisa-ação dados são participados à

[...] coletividade a fim de conhecer sua percepção da realidade e de orientá-la de modo a permitir uma avaliação mais apropriada dos problemas detectados. Os exames dos dados visam redefinir o problema e encontrar soluções. (BARBIER, 2004, p. 55)

Os dados apresentados neste artigo foram discutidos com os participantes da pesquisa conforme análise construída e compartilhada durante sua elaboração.

\section{BASTIDORES (DES)VELADOS NO CONTEXTO DE UMA ESCOLA PÚBLICA}

Nesta seção optamos por desenvolver nossas argumentações em torno da organização das turmas na escola (enturmação), tema que emergiu dos dados construídos no processo de composição de turmas adotado na escola e sua relação direta com o lugar físico e simbólico que estudantes com deficiência tinham no currículo escolar.

Na escola campo da pesquisa, apesar de as séries distribuírem-se em turmas A, B e C, os 17 estudantes com deficiência - número de alunos matriculados na escola em 2013 - estavam agrupados nas turmas do $6^{\circ}$ ao $9^{\circ}$ ano $C$. As turmas $C$ eram explicitamente organizadas como a "classe dos atrasados", haja vista o agrupamento de estudantes em situações de vulnerabilidade escolar seja por suas idades avançadas, seja por deficiência e/ou comportamento indisciplinado. A turma era estigmatizada, emergiu um cunho patologizante e de negação às suas possibilidades de aprendizagem. 
Essa organização - estudantes com deficiência na turma C - não despertava atenção dos sujeitos da escola e foi preciso problematizar com eles:

Olha nós temos esse agrupamento no sentido de que foi uma necessidade que a própria Instituição Especial pediu. Que eles permanecessem juntos, né? Pra não terem tantas dificuldades, que um ajudasse ao outro. [...] E eles se fecharam muito nesse grupo. Eles continuaram fechados. (Entrevista, professora Betânia, 04/11/2013)

Outro relato, dessa vez resultante de uma das atividades em grupo apresentada no GCEI e registrado no diário de campo das colaboradoras, reforça a escolha do agrupamento dos estudantes com deficiência na turma $C$ :

O primeiro grupo apresenta a atividade. Inicialmente explicaram que fizeram uma retrospectiva da experiência com os cegos quando chegaram à escola. Pontuam como foram os primeiros contatos com os alunos com deficiência e a orientação da Instituição Especial para deixá-los na mesma turma. (Diário de campo das colaboradoras, 24/10/2013)

Embora a matrícula dos estudantes com deficiência visual tenha sido a primeira experiência da escola em 2010, havia o registro de outras deficiências em 2013, como no caso do $6^{\circ}$ ano, em que se observava matrícula de seis estudantes: dois com deficiência intelectual, um com deficiência física, dois com baixa visão e uma estudante surda. Contudo, a indicação da instituição especial para o agrupamento dos estudantes com deficiência visual prevalecia e se estendia a outras deficiências, ao ponto de os professores não se importarem com o agrupamento de deficiências distintas, como a surdez e a visual, em uma mesma sala. Conforme acreditamos, o que importa é que a validação dessa prática nunca fora questionada porque vinda do "especialista” e porque criou uma "zona de conforto" nos processos de interação social mistos. Além disso, a disposição dos estudantes nas turmas $C$ reforçava o descrédito aos demais alunos, tidos como os "atrasados", e correspondia a um procedimento de escolhas em torno de comportamentos, ou da formação de grupos com homogeneidade em determinados aspectos.

Seja por quais fossem as alegações, o agrupamento dos estudantes com deficiência interferia no modo como os professores concebiam a deficiência, partindo inclusive do ponto de vista de que esses alunos aprenderiam melhor em contato com os "iguais" e não com os demais estudantes das turmas. Com efeito, embora tivéssemos avançado nas discussões com os participantes da pesquisa acerca da inclusão escolar 
de estudantes com deficiência, ainda restaram as desafiadoras situações advindas da interação com esses estudantes, principalmente quando se reconheciam atitudes estigmatizadoras no espaço escolar.

A constatação das dificuldades docentes em reconhecer a deficiência como não definidora da identidade de diferentes estudantes em seus modos de aprender levou-nos a discutir o tema com os participantes do GCEI de forma ética, crítica e reflexiva. As discussões sobre as enturmações foram recorrentes nos 32 encontros formativos do GCEI, pois, inicialmente, os professores foram unânimes em defender a comodidade desse agrupamento para os estudantes com deficiência, alegando ser um fator positivo no processo de escolarização desses estudantes.

Constatamos, então, que alguns participantes consideravam a existência da turma $C$ com aquela configuração como obviamente o mais "adequado" e, portanto, não havia necessidade de problematizações. Era uma decisão de cunho político e pedagógico cristalizada na organização curricular da escola. Desse modo, o desafio residia, em parte, na transformação da cultura escolar, por sua vez, caracterizada por uma visão estigmatizadora sobre os processos de aprendizagem dos "alunos da turma C”, notadamente os estudantes com deficiência.

Justificativas explícitas ou implícitas perpassavam o argumento dos sujeitos da pesquisa para manutenção dos agrupamentos. Subliminarmente a ideia de que a marca da deficiência caracteriza os modos de ser e agir de diferentes pessoas, como se todas agissem de um mesmo modo e para elas construíssemos um mesmo cabedal metodológico baseado em seus déficits, também corroborou para a concepção de que ter tais estudantes numa mesma sala facilitaria ao professor lidar com suas especificidades:

A pesquisadora faz um levantamento das ideias dos professores a
respeito dos estudantes com deficiência estudarem juntos numa
mesma turma. Um dos argumentos apresentados pelos professores
foi o de facilitar o trabalho docente, porque lida com as deficiências
na mesma aula. (Diário de campo da colaboradora, 25/09/2013)

Eu estou lembrando daquele dia que você estava discutindo aí na formação que não era bom, não é, porque já era uma forma de discriminar, né? Agora assim, mas se a gente for ver o lado do professor, pra eles, eles afirmam que é melhor, porque ai ele se desgasta menos [...] Se fosse em salas diferentes eles agrupados em outras salas, eles acham que se desgastariam mais, né? O professor... Até eles já colocaram isso pra gente. (Entrevista, professora Viviane, 19/11/2013)

Contraditoriamente, não identificamos nas práticas, nem nas entrevistas dos professores da Escola Estadual Despertar, quaisquer 
referências a adaptações de conteúdo, avaliação ou estratégias pedagógicas nas aulas das turmas $\mathrm{C}$, como revela um excerto a seguir:

\begin{abstract}
A pesquisadora convoca os professores a refletirem sobre o descrédito da turma C e como a organização das turmas pode interferir na aprendizagem dos estudantes. Os professores ficam surpresos com os argumentos da pesquisadora sobre o planejamento para as turmas. O professor Miguel questiona se o argumento sobre a distribuição dos estudantes com deficiência funciona. A professora Jaque questiona que colocar o aluno na turma A, pode fazer com que o estudante com deficiência se sinta inferior. A pesquisadora interroga se os processos avaliativos nessas turmas são diferenciados e os professores afirmam que as provas são iquais, mas que os rendimentos são diferentes, mais baixos que nas outras turmas. (Diário de campo das colaboradoras, 26/09/2013)
\end{abstract}

Estudantes com histórico de fracasso escolar, agrupados em uma só turma, acentuaram a necessidade de discutirmos o currículo de forma a evitar excessivas particularizações acerca das demandas de alunos com deficiência. Optamos por problematizar com os sujeitos da pesquisa a real participação nas aulas de todos os estudantes e qual o sentido dado a estes para o que lhes era ensinado em situações de aula marcadas por uma perspectiva meramente transmissiva do conhecimento. Isso porque a presença dos estudantes com deficiência nas turmas $\mathrm{C}$, embora fosse um dado importante para nossa investigação e, que, portanto, necessitava de uma maior atenção, possuía uma implicação mais profunda do que sua aparente organização em função de uma orientação advinda de uma instituição especializada. A presença de tais alunos na turma $\mathrm{C}$ dizia respeito à forma como a escola organizava suas turmas permeadas por estigmas. As discussões permitiram aos professores refletirem sobre essa prática da organização curricular pautados pela sustentação teórica oportunizada durante os momentos formativos no GCEI, tal como evidenciam os excertos a seguir:

\footnotetext{
Eu acho que, não sei, não sei porque tem uma explicação pra eles tarem juntos, né? Se a gente aprende com as diferenças e que seria muito mais proveitoso se eles tivessem, é um contato com outras pessoas que não são deficientes, ou que tem outros tipos de deficiências, que poderia enriquecê-los, né? E adquirir mais experiências e até pelo fato da interação mesmo, de não tá interagindo só com aquele grupo. É então acredito que, seja... não sei por que está desse jeito, mas que é uma coisa que tem que ser repensada. (Entrevista professora da SRM Raquel, 05/11/2013)
} 
No trecho de outra entrevista, a reflexão sobre os prejuízos dos agrupamentos para outros estudantes se evidencia:

\begin{abstract}
Eu acho esses agrupamentos, como eu já falei [referindo-se às suas participações no GCEl] com você, né? Eu acho muito desnecessário, usando uma palavra assim, eu achei um absurdo! Porque é mais ou menos você não dar a devida oportunidade pro aluno, né? É dizer que ele não consegue, colocar ele lá e ponto, então aquela sala ali é a sala dos que não conseguem! E todos os alunos que vêm pro 6ㅇ C são os alunos reprovados, os alunos com necessidades especiais, que têm alguma dificuldade! E aí já caracterizou eles como os alunos que não conseguem, né? E aí eles não conseguem avançar. (Entrevista da intérprete de Libras Diná, 26/11/2013, grifo nosso)
\end{abstract}

Problematizada com os participantes, a organização das turmas começava a ser questionada e não apenas para os estudantes com deficiência, afinal sua prática desvelava uma forma perversa de categorizar os sujeitos. Nos anos subsequentes, a escola passou a inserir os estudantes "atrasados" nas demais turmas, o que denota uma reorganização pedagógica dos processos de ensinar e aprender, em especial as concepções sobre as condições de aprendizagem dos sujeitos estigmatizados.

Situações de “descuido" com a aprendizagem dos estudantes passaram a compor nossos diálogos no GCEI. Com os sujeitos conversávamos sobre outras possibilidades quanto à participação de estudantes com deficiência e alargávamos as discussões de que a atenção para as suas condições de acessibilidade e participação ao currículo escolar poderia ser proveitosa para os demais estudantes:

\footnotetext{
Os demais alunos também são beneficiados, né? Porque no caso da, pensando na deficiência visual, é, o que se precisa são de detalhamentos das informações, né? De situações, e, assim: quanto mais detalhado, quanto mais informações forem passadas pra eles, fica, creio eu que fica mais fácil pra eles assimilarem, quanto mais detalhado for. (Entrevista, professor Geraldo, 05/11/2013)
}

Além da composição de turmas e das possibilidades de reorganização das práticas curriculares, a investigação evidenciou o lugar simbólico do aluno com deficiência intelectual no contexto do dia a dia da escola, tais como as formas de participação dos estudantes com deficiência nas aulas. Seu cotidiano transcorria, em geral, da seguinte forma: 
olhando para trás sorri para mim, ao que respondo com outro sorriso. Depois se volta para frente e continua a copiar. (Diário de campo da pesquisadora, 17/06/2013)

Após explicação do conteúdo os estudantes começam a fazer a atividade no livro. Felipe, estudante com deficiência intelectual, sentado no fundo da sala, permanece com o livro aberto, porém não responde a atividade. Espera que os colegas façam para copiar. (Diário de campo da pesquisadora, 08/08/2013)

As discussões estabelecidas no GCEI trouxeram à tona, também, a evidente invisibilidade da deficiência intelectual. É possível afirmar, assim, que nas situações narradas podemos vislumbrar as seleções no/do currículo escolar, nas quais subjazem relações de poder, algo de certa forma já anunciado em nosso referencial teórico, pois o currículo é sempre parte de uma

\begin{abstract}
[...] tradição seletiva, resultado da seleção de alguém, da visão de algum grupo acerca do que seja conhecimento legítimo. É produto das tensões, conflitos e concessões culturais, políticas e econômicas que organizam e desorganizam um povo. (APPLE, 2008, p. 59, grifo do autor)
\end{abstract}

Nesse sentido a presença de estudantes com deficiência nas salas de aula e as discussões estabelecidas no GCEI acerca de suas próprias práticas desafiavam os participantes, colocando-os diante de suas concepções e crenças nem sempre consoantes com os conteúdos discutidos no âmbito das políticas de inclusão escolar.

As situações observadas no contexto escolar evidenciavam que os sujeitos necessitavam de ações colaborativas e da oportunidade de reflexão sobre suas próprias práticas. Nos encontros do GCEI houve adensamento das discussões, nas quais os professores revelavam seus receios em marginalizar esses estudantes, a aparente aceitação desses estudantes nas turmas e, ao mesmo tempo, certa comodidade em não lhes dirigir atenção no manejo da prática educativa. Aos poucos os professores revelavam seus estranhamentos:

A professora Aurilene afirmou que muitas vezes não sabia como agir, se sentia só e isso dificultava o trabalho. (Diário de Campo da pesquisadora. Fala da professora Aurilene, 24/10/2013)

No começo foi um choque a gente nunca tá preparado para o desconhecido, deveria ser natural, mas não foi, no início não foi. Foi muito assustador porque eu fiquei: como vou fazer? Como vou fazer pra que haja melhor aprendizado, suava muito, bastante (risos), 
ficava um pouco nervosa, não demonstrava muito, mas a gente vai abrindo os caminhos e vai conseguindo! (Entrevista, professora de Ciências Nora, 08/11/2013)

As ações voltadas à inclusão escolar de estudantes com deficiência no contexto da escola investigada ainda eram, notadamente, apoiadas no descrédito e não no direcionamento das condições de aprendizagem desses estudantes. Conforme podemos observar no excerto das falas dos sujeitos transcritas a seguir:

O professor Júnior afirmou que os estudantes cegos faziam as provas gerais na SRM e que só compareciam no dia que queriam. Os professores José, Nora e Alice falaram que ficavam cheios de dedos nessas situações. (Diário de campo da pesquisadora, 09/09/2013. Encontro do GCEI)

Após a explanação realizada com bastante propriedade, o professor passou a escrever o apontamento no quadro. Os estudantes cegos não copiavam e alegavam a falta de papel braile como justificativa, muito embora todos possuíssem note book. Apenas Jerônimo havia levado o seu, então digitava e repassava para os demais. (Diário de campo da pesquisadora, 07/08/2013. Aula do professor de História: José. Conteúdo: Colonização Americana, 9ano C)

\begin{abstract}
A professora iniciou a aula pontualmente. Fez a chamada e logo depois iniciou a explicação do conteúdo - estrutura de artigo de opinião. Os estudantes cegos, de cabeça baixa, relutavam em participar das discussões. (Diário de campo da pesquisadora, 04/09/2013. Aula da professora Paula. Língua Portuguesa. Conteúdo: Artigo de Opinião, 9ano C)
\end{abstract}

Embora tenhamos constatado as dificuldades dos participantes em lidar com especificidades desses estudantes, o desenvolvimento do GCEI possibilitou-nos evidenciá-las e discuti-las sob uma perspectiva ainda não considerada na escola. Questionamos o porquê de os estudantes com deficiência visual poderem transitar livremente no espaço escolar em horários nos quais isso era proibido para todos os outros estudantes e como os professores poderiam ampliar a participação de tais estudantes e aprendizagem na sala de aula, como observado nos episódios descritos a seguir:

Outro aspecto discutido foram as regalias dos estudantes cegos. Os professores informavam não saber como agir. Problematizamos situações observadas em sala de aula como a não participação dos estudantes com deficiência em atividades comuns aos demais 
estudantes. O professor José externou: "Olha, eu vejo que pra eles tá muito confortável, quando a gente solicita que eles participem, eles dizem que não precisa! Desse jeito é difícil trabalhar!" Questionei ao professor José e aos demais qual era a atitude tomada quando outro estudante sem deficiência desse esse tipo de resposta. Os professores foram unânimes em afirmar que esses estudantes teriam que desenvolver as atividades, ou poderiam ficar em suas casas. Com as discussões chamamos atenção para o fato de que envolver estudantes com e sem deficiência nas atividades propostas deveria ser objetivo comum. O cuidado requerido deveria ser tão somente as condições para que estudantes com deficiência tivessem acesso às atividades, todavia, as exigências de participação e cumprimento da tarefa deveriam ser comuns a toda turma. (Diário de campo da pesquisadora, 09/09/2013. Encontro do GCEI)

A medida em que as informações foram compartilhadas, um professor disse: "muito bom!" Esse é um dado que nos interessa, pois não sabiamos exatamente como tratar o estudante com deficiência! (Diário de campo da pesquisadora, 09/09/2013. Encontro do GCEI)

Identificamos a não garantia de uma proposta de formação continuada na escola e o decorrente isolamento das práticas pedagógicas realizadas como um dos principais obstáculos ao trabalho do professor. Para Sacristán (2000, p. 198), a coletividade

[...] da profissionalização docente para desenvolver um currículo coerente para os alunos é uma necessidade urgente entre nós. $\bigcirc$ isolamento nas aulas supõe a falta de questionamento das estruturas e decisões que dependem de instâncias coletivas.

O fato de os professores não socializarem seu planejamento e seus desafios cotidianos com seus colegas contribuía para ausência de reflexão das práticas docentes e privava os sujeitos da escola da troca de informações sobre especificidades de estudantes com deficiência e dos demais, e, especialmente, sobre possibilidades para um trabalho diversificado para todos os estudantes.

Nosso estudo evidencia que "a inclusão se apresenta como 'campo de forças' e embates, e não somente como terreno de competência técnica de professores e gestores" (MAGALHÃES, 2012, p. 502). Portanto, o "como fazer" na sala de aula não se esgota na dimensão técnica do saber especializado para adaptação de um determinado recurso, um plano individualizado para o estudante com deficiência, a flexibilização curricular. Essas formas de intervenção educativa ganham sentido quando 
refletidas na trama de conflitos e no questionamento de interesses, ideologias e (in)definições do que se elege como conhecimento escolar para diferentes estudantes, ou seja, além da dimensão técnica, na dimensão crítica desse mesmo currículo.

A escola revelou, gradativamente, a intrincada relação das dimensões técnicas e simbólicas ligadas ao currículo, personificada no acesso desigual e injusto dos estudantes com deficiência à parte do conhecimento produzido pela humanidade. Parece-nos, então, que a revisão de metodologias para fazer os conteúdos acessíveis a todos os estudantes é assunto recorrente para prática de muitos professores. Nivelados conforme suas supostas (in)capacidades, os estudantes estavam imersos numa teia de rotulações que os distanciava do acesso e participação no currículo escolar. Mais uma vez, o "inocente” mecanismo para agrupamento dos estudantes com deficiência em uma única turma transversalizou os momentos formativos desenvolvidos ao longo da investigação e indicou a necessidade de desenvolver temas voltados à compreensão do currículo escolar como avivador ou silenciador das vozes e da participação de diferentes estudantes.

\section{CONCLUSÕES}

Nossa investigação revelou a complexidade de pensar as diferenças no contexto escolar, não como rótulo atraente sobre como "incluir" estudantes com deficiência nos processos de escolarização, afinal tal inclusão não se esgota com pequenos ajustes organizacionais ou curriculares, mas exige desse contexto escolar a transformação do cotidiano com base no

[...] exercício da autonomia do pensamento, através do exercí-
cio da convivência e do diálogo, pois somente assim poderemos
aprender a ouvir o outro, ouvir nós mesmos, fazer concessões, vi-
ver intensamente a pluralidade de ideias. (OLIVEIRA, 2002, p. 303)

Advogamos a pertinência de propostas investigativas sob o crivo da pesquisa-ação colaborativo-crítica com ênfase na inclusão escolar, como favorecedoras das condições de escolarização não somente de estudantes com deficiência, mas para estudantes não "enquadrados" como deficientes que vivenciam os efeitos de um processo de ensino aprendizagem com prejuízos ao seu desenvolvimento educacional.

Na escola campo da pesquisa foram intensas as discussões a respeito da proposta curricular e da necessidade de problematização dessa proposta. No contato com os participantes da pesquisa, aprendemos sobre o imperativo da abertura aos diálogos acerca do currículo e da inclusão de estudantes com deficiência, aprendemos a ouvir a palavra desses professores e apontar possibilidades de reflexão. 
Entendemos a intervenção vivenciada não como um modelo formativo, mas sim como a proposição de que a formação seja permanente, como defende Freire (2001, 2003), e a escola, um espaço aberto e sensível à socialização de dúvidas e experiências, no qual há troca de informações, impressões e saberes. O sentido colaborativo-crítico da pesquisa permitiu-nos realizar a investigação com mais segurança, autonomia e diríamos até ousadia sem descuidar da dimensão ética.

Pensar sobre a prática curricular foi o movimento produzido pela pesquisa; além disso, para alguns professores foi a primeira formação realizada no tocante à inclusão escolar de estudantes com deficiência.

A investigação com sua faceta crítico-colaborativa possibilitou refletir com os participantes sobre a tarefa da escola em promover condições de aprendizagem para todos os estudantes. Com efeito, gradativamente, identificamos mudanças nas práticas dos professores, por exemplo, nascidas das reflexões e dos embates vividos durante o percurso da pesquisa.

A confiança necessária para iniciarmos os diálogos fez crescer em nossas constatações e necessidade de mudanças nas práticas observadas. A não adaptação dos estudantes na escola e suas dificuldades no acompanhamento de atividades e conteúdos necessitaram de uma análise mais aprofundada. Foi preciso questionar, durante os encontros formativos, se a escolarização oferecida aos demais estudantes correspondia às suas necessidades e ao esperado convencionalmente da escola enquanto instituição formativa.

Com relação ao agrupamento de estudantes com deficiência em única turma, os professores informaram que a escola, no ano subsequente ao de nossa investigação, mudou sua perspectiva ao diluir tais estudantes nas variadas turmas. Convidamos os participantes a refletirem sobre a importância de garantir a continuidade da proposta formativa no interior da própria escola, afinal, conforme consideramos, a mera distribuição dos estudantes com deficiência nas outras turmas da escola seria insuficiente para garantir as condições de participação e desenvolvimento desses alunos.

Na teia de conflitos e resistências expressos nas falas e práticas da maioria dos professores da escola, as mudanças provocadas indicavam a existência de outras formas de organização do currículo escolar e que, talvez, o não atentar para as potencialidades dos estudantes com deficiência não fosse a decisão mais acertada. Como afirmou Apple (1999), a escola não apenas reproduz, mas é um espaço para a construção de processos formativos que ousem questionar as obviedades, as regularidades da vida escolar.

Outrossim, muitas das discussões estabelecidas nos encontros do GCEI dizem respeito à prática curricular em sua totalidade, e não apenas aos aspectos concernentes à inclusão escolar de estudante com deficiência. É imperioso "contemplar las diferencias como oportunidades de aprendizaje y no como problemas que solucionar” (AINSCOW, 2001, p. 32). Essas discussões pautadas pelas observações realizadas, entrevistas, 
bem como a aproximação aos debates teóricos existentes, encaminham-nos ao reconhecimento da problematização da escolarização desse estudante como possibilidade de (re)pensar das práticas curriculares para/na escola como um todo e nisso reside um paradoxo, pois, se, por um lado, não se trata de minimizar o conhecimento específico no trato das necessidades de estudantes com deficiência, por outro, tampouco interessa-nos distanciar tais necessidades daquelas inerentes à natureza humana, portanto peculiares aos demais estudantes.

A problematização do currículo apresenta-se como incontestável tarefa da educação e, portanto, permanece como importante na forma de retroalimentar as práticas de inclusão escolar desenvolvidas no campo educacional brasileiro.

\section{REFERÊNCIAS}

AINSCOW, Mel. Desarrollo de escuelas inclusivas: ideas, propuestas y experiencias para mejorar las instituciones escolares. Madrid: Narcea, 2001.

ALMEIDA, Mariângela Lima de. Formação continuada como processo crítico-reflexivo-colaborativo: possibilidades de construção de uma prática inclusiva. 2004. 267 f. Dissertação (Mestrado em Educação) - Universidade Federal do Espírito Santo, Vitória, 2004.

ALMEIDA, Mariângela Lima de. Uma análise da produção acadêmica sobre os usos da pesquisa-ação em processos de inclusão escolar: entre o agir comunicativo e o agir estratégico. 2010. $233 \mathrm{f}$. Tese (Doutorado em Educação) - Universidade Federal do Espírito Santo, Vitória, 2010.

AMARAL, Míriam Matos. A inclusão de crianças com necessidades educacionais especiais na educação infantil: uma análise do currículo moldado pelas práticas pedagógicas de professoras da rede municipal de ensino de Belém. 2006. 148 f. Dissertação (Mestrado em Educação) - Universidade Federal do Pará, Belém, 2006.

APPLE, Michael W. Ideologia e currículo. São Paulo: Brasiliense, 1982.

APPLE, Michael W. Educação e poder. Porto Alegre: Artmed, 1989.

APPLE, Michael W. Repensando ideologia e currículo. In: MOREIRA, Antônio F.; SILVA, Tomaz. Currículo, cultura e sociedade. 3. ed. São Paulo: Cortez, 1999. p. 39-58.

APPLE, Michael W. A política do conhecimento oficial: faz sentido a idéia de um currículo nacional? In: MOREIRA, Antonio Flávio; SILVA, Tomaz Tadeu da. (Org.). Currículo, cultura e sociedade. 10. ed. São Paulo: Cortez, 2008. p. 59-92.

BARBIER, Renné. A pesquisa-ação na instituição educativa. Tradução de Estela dos Santos Abreu com colaboração de Maria Wanda Maul de Andrade. Rio de Janeiro: Jorge Zahar, 1985.

BARBIER, Renné. A pesquisa-ação. Tradução de Lucie Didio. Brasília: Líber Livro, 2004.

BUENO, José Geraldo. As políticas de inclusão escolar: uma prerrogativa da educação especial? In: BUENO, José Geraldo; MENDES, Geovana; SANTOS, Roseli. Deficiência e escolarização: novas perspectivas de análise. Brasília: Junqueira \& Marin, 2008. p. 43-63.

CARVALHO, Rosita Edler. Escola inclusiva: a reorganização do trabalho pedagógico. Porto Alegre: Mediação, 2008.

EFFGEN, Ariadna Pereira Siqueira. Educação especial e currículo escolar: possibilidades nas práticas pedagógicas cotidianas. 2011. 227 f. Dissertação (Mestrado em Educação) - Universidade Federal do Espírito Santo, Vitória, 2011.

FERREIRA, Maria Cecília Carareto; FERREIRA, Júlio Romero. Sobre inclusão, políticas públicas e práticas pedagógicas. In: LAPLANE, Adriana Lia Friszman de (Org.). Políticas e práticas de educação inclusiva. Campinas: Autores Associados, 2004. p. 21-48. (Educação Contemporânea). 
FIORINI, Maria Luiza Salzani; DELIBERATO, Débora; MANZINI, Eduardo José. Estratégias de ensino para alunos deficientes visuais: a proposta curricular do estado de São Paulo. Motriz, Rio Claro, v. 19, n. 1, p. 62-73, jan./mar. 2013.

FONSECA, Katia Abreu. Análise de adequações curriculares no ensino fundamental: subsídios para programas de pesquisa colaborativa na formação de professores. 2011. 124 f. Dissertação (Mestrado em Psicologia do Desenvolvimento e Aprendizagem) - Universidade Estadual Paulista "Júlio de Mesquita Filho", Bauru, 2011.

FONSECA, Katia Abreu; CAPELLINI, Vera Lúcia Messias Fialho; LOPES JUNIOR, Jair.

Flexibilização e adaptação curricular no processo de inclusão escolar. In: VALLE, Tânai Gracy Martins do; MAIA, Ana Cláudia Bortollozi (Org.). Aprendizagem e comportamento humano. São Paulo: Cultura Acadêmica, 2010. p. 17-34.

FORQUIN, Jean-Claude. Escola e cultura: as bases sociais e epistemológicas do conhecimento escolar. Porto Alegre: Artes Médicas, 1993.

FRANCO, Maria Amélia Santoro. Pedagogia da pesquisa-ação. Educação e Pesquisa, São Paulo, v. 31, n. 3, p. 483-502, set./dez. 2005.

FREIRE, Paulo. Pedagogia dos sonhos possíveis. São Paulo: Unesp, 2001.

FREIRE, Paulo. Professora sim, tia não: cartas a quem ousa ensinar. 14. ed. São Paulo: Olho d'Água, 2003.

GARCIA, Rosalba Maria Cardoso. Políticas para a educação especial e as formas organizativas do trabalho pedagógico. Revista Brasileira de Educação Especial, Marília, v. 12, n. 3, p. 299-316, set./dez. 2006.

GIVIGI, Rosana Carla do Nascimento. Tecendo redes, pescando idéias: (re)significando a inclusão nas práticas educativas da escola. 2007. 233 f. Tese (Doutorado em Educação) - Universidade Federal do Espírito Santo, Vitória, 2007.

GLAT; Rosana; PLETSCH, Marcia Denise. Inclusão escolar de alunos com necessidades especiais. Rio de Janeiro: EdUERJ, 2011. (Pesquisa em Educação. Educação Inclusiva).

GOFFMAN, Erving. Estigma: notas sobre a manipulação da identidade deteriorada. 4. ed. Rio de Janeiro: Guanabara, 1988.

GONÇALVES, Aline Kelly Scalco. Estratégias pedagógicas inclusivas para crianças com paralisia cerebral na educação infantil. 2006. 136 f. Dissertação (Mestrado em Educação Especial) Universidade Federal de São Carlos, São Carlos, 2006.

GONZAGA, Amarildo Menezes. A pesquisa em educação: um desenho metodológico centrado na abordagem qualitativa. In: PIMENTA, Selma Garrido; GHEDIN, Evandro; FRANCO, Maria Amélia Santoro (Org.). Pesquisa em educação: alternativas investigativas com objetos complexos. São Paulo: Loyola, 2006. p. 65-92.

INSTITUTO NACIONAL DE ESTUDOS E PESQUISAS EDUCACIONAIS ANÍSIO TEIXEIRA - INEP. Censo escolar da educação básica. 2013. Disponível em: <http://www.inep.gov.br/basica-censoescola-matricula>. Acesso em: 2 fev. 2015.

JESUS, Denise Meyrelles de. O que nos impulsiona a pensar a pesquisa-ação colaborativa-crítica como possibilidade de instituição de práticas mais inclusivas? In: BAPTISTA, Cláudio Roberto; CAIADO, Kátia Regina Moreno; JESUS, Denise Meyrelles de (Org.). Educação especial: diálogo e pluralidade. Porto Alegre: Mediação, 2008. p. 139-159.

JESUS, Denise Meyrelles de; ALMEIDA, Mariangela Lima de; SOBRINHO, Reginaldo Célio. Pesquisa-ação-crítico-colaborativa: implicações para a formação continuada e a inclusão escolar. In: REUNIÃO ANUAL DA ANPED, 28., 2005, Caxambu. Anais... Caxambu: Anped, 2005.

KLEIN, Madalena; FORMOZO, Daniele de Paula. Im/possibilidades na educação de surdos: discussões sobre currículo e diferença. Currículo sem Fronteiras, v. 9, n. 2, p. 212-225, jul./dez. 2009.

LOPES, Esther. Adequação curricular: um caminho para a inclusão do aluno com deficiência intelectual. 2010. 166 f. Dissertação (Mestrado em Educação) - Universidade Estadual de Londrina, Londrina, 2010.

MAGALHÃES, Rita de Cássia Barbosa Paiva. Ditos e feitos da educação inclusiva: navegações pelo currículo escolar. 2005. 255 f. Tese (Doutorado em Educação) - Universidade Federal do Ceará, Fortaleza, 2005. 
MAGALHÃES, Rita de Cássia Barbosa Paiva. Falem com elas: construir diálogos na escola inclusiva. In: MAGALHÃES, Rita de Cássia Barbosa Paiva (Org.). Educação inclusiva: escolarização, política e formação docente. Brasília: Liber Livro, 2011. p. 13-33.

MAGALHÃES, Rita de Cássia Barbosa Paiva. Currículo em educação especial: dimensões técnicas e políticas em discussão. In: MENDES, Enicéia Gonçalves; ALMEIDA, Maria Amélia (Org.). Dimensões pedagógicas nas práticas de inclusão escolar. Marília: ABPEE, 2012. p. 491-507. (Inclusão Escolar, v. 2).

MANJÓN, Daniel González (Org.). Adaptaciones curriculares: guía para su elaboración. Málaga: Aljibe, 1995.

NÓVOA, António. Formação de professores e trabalho pedagógico. Lisboa: Educa, 2002.

OLIVEIRA, Anna Augusta Sampaio de. Representações sociais sobre educação especial e deficiência: o ponto de vista de alunos deficientes e professores especializados. 2002. 325 f. Tese (Doutorado em Educação) - Universidade Estadual Paulista “Júlio de Mesquita Filho”, Marília, 2002.

OLIVEIRA, Anna Augusta Sampaio de. Formas de organização escolar: desafios na construção de uma escola inclusiva. In: OMOTE, Sadao (Org.). Inclusão: intenção e realidade. Marília: Fundepe, 2004. p. 77-112.

PIMENTA, Selma Garrido. Pesquisa-ação crítico-colaborativa: construindo seu significado a partir de experiências na formação e na atuação docente. In: PIMENTA, Selma Garrido; GHEDIN, Evandro; FRANCO, Maria Amélia Santoro (Org.). Pesquisa em educação: alternativas investigativas com objetos complexos. São Paulo: Loyola, 2006. p. 25-64.

SACRISTÁN, J. Gimeno. 0 currículo: uma reflexão sobre a prática. Tradução de Ernani Rosa. 3. ed. Porto Alegre: Artmed, 2000.

SILVA, Fabiany de Cássia Tavares. Desenhando a cultura escolar: ensinoaprendizagem e deficiência mental nas salas de recursos e nas salas comuns. In: MENDES, Enicéia; ALMEIDA, Maria Amélia; HAYASHI, Maria Cristina. Temas em educação especial: conhecer para fundamentar a prática. Brasília: Junqueira \& Marina, 2008. p. 67-107.

SILVA, Fabiany de Cássia Tavares. Entre o processo civilizador e a gestão controlada do currículo: a escola inclusiva “dos deficientes". Currículo sem Fronteiras, v. 10, n. 2, p. 214-227, jul./dez. 2010.

SILVA, Tomaz Tadeu. Documentos de identidade: uma introdução às teorias do currículo. 2. ed. Belo Horizonte: Autêntica, 2007.

STAKE, Robert E. Pesquisa qualitativa: estudando como as coisas funcionam. Porto Alegre: Penso, 2011.

VIEIRA, Alexandro Braga. Práticas pedagógicas e formação continuada de professores no ensino da língua materna: contribuições para a inclusão escolar. 2008. 246 f. Dissertação (Mestrado em Educação) - Universidade Federal do Espírito Santo, Vitória, 2008.

VIEIRA, Alexandro Braga. Currículo e educação especial: as ações da escola a partir dos diálogos cotidianos. 2012. 327 f. Tese (Doutorado em Educação) - Universidade Federal do Espírito Santo, Vitória, 2012.

VYGOTSKY, L. S. A formação social da mente. 2. ed. Tradução de José Cipolla Neto, Luis Silveira Menna Barreto e Solange Castro Afeche. São Paulo: Martins Fontes, 1988. (Psicologia e Pedagogia).

\section{RITA DE CÁSSIA BARBOSA PAIVA MAGALHÃES}

Professora da Universidade Federal do Rio Grande do Norte - UFRN -, Natal, Rio Grande do Norte, Brasil

ritafora@hotmail.com

\section{MARCIA TORRES NERI SOARES}

Professora da Universidade do Estado da Bahia - Uneb -, Ipiaú, Bahia, Brasil profa.marciatorres@gmail.com 